\title{
O SUICÍDIO EM SEU MOSTRAR-SE A PROFISSIONAIS DE SAÚDE ${ }^{1}$ \\ THE SUICIDE IN ITS TO REVEAL IT PROFESSIONAL OF HEALTH ${ }^{1}$ EL SUICIDIO REVELÁNDOSE A LOS PROFIESIONALES DE LA SALUD ${ }^{1}$
}

\section{Viviane Picinato da Silva ${ }^{2}$ Magali Roseira Boemer ${ }^{3}$}

\begin{abstract}
RESUMO: O aumento no número de casos e tentativas de suicídio vem sendo alvo de grande preocupação, nas últimas décadas, em muitos países. Frente às minhas observações e à consulta à literatura, deparei-me com uma inquietação: Estarão os profissionais que cuidam de pessoas, com história de tentativa de suicídio, preparados para lidar com essa situação? O estudo foi conduzido sob o referencial da Metodologia de Investigação Fenomenológica, contando com a participação de profissionais médicos, enfermeiros e auxiliares de enfermagem que atuam na Clínica Psiquiátrica da Unidade de Emergência do Hospital das Clínicas da Faculdade de Medicina de Ribeirão Preto - USP, no período de julho a agosto de 2003. Foi proposta a seguinte questão norteadora: "Como o suicídio se mostra a você?" Após realizar a análise dos depoimentos foram construídas categorias temáticas desvelando, assim, que o suicídio se mostra a esses profissionais como algo que ocorre num momento de muito desespero, ao qual as pessoas recorrem para chamar atenção e algo que lhes desperta uma diversidade de sentimentos. Da análise dos depoimentos, foi possível compreender que o estudo evidencia necessidade de se introduzir, na área de saúde mental, profissionais especializados. A especialização possibilita aos profissionais lidar melhor com os preconceitos e dificuldades, abrindo assim, perspectivas para um melhor cuidado às pessoas que não vêem sentido na própria vida.

PALAVRAS-CHAVES: Suicídio, Tentativa de Suicídio; Saúde Mental.
\end{abstract}

ABSTRACT: The number of suicide case and attempting are increasing at last decades and became a great concern in many countries. In front to my observations and literature consulting, an important question emerged from: Do the professional who care people with attempting suicide history are prepared to deal with this situation? This study was conduced on a Phenomenological Inquiry method with medicine doctors, nurses and nursing staff professionals Psychiatric Clinic at the Emergency Unity of the Sao Paulo - Ribeirão Preto Clinical Hospital, from July to August 2003. The following guiding question was proposed: How suicide shows for you? From interviewing answers analysis, thematic categories was constructed revealing, thus, that the suicide is shown to these professionals as something that occurs at a desperation moment, which people appeals to call attention and something that awakes to them a diversity of feelings. From speeches analysis was possible to understand that the study evidences the necessity of introducing, in mental health area, specialized professionals. The specialization makes possible to the professionals to better deal with the preconceptions and difficulties, thus opening, perspectives for a better care to the people whom do not perceive sense in their own lives.

KEYWORDS: Suicide, Suicide, Attempted; Mental Health.

RESUMEN: El aumento del número de casos y tentativas de suicidio están siendo objeto de gran preocupación, en las últimas décadas, en muchos países. Ante mis observaciones y la consulta de literatura, me deparé con una inquietud: ¿Los profesionales que tratan de personas con historia de tentativa de suicidio están preparados para enfrentar esa situación? El estudio fue conducido bajo el referencial del Metodología de Investigación Fenomenológica, contando con la participación de profesionales médicos, enfermeros y auxiliares de enfermería que actúan en el Clínica Psiquiátrica del Unidad de Emergencia del Hospital de Clínicas de Ribeirao Preto del Universidad de Sao Paulo, en el período de julio a agosto de 2003. Se propuso la siguiente cuestión orientadora: “¿Cómo se le revela el suicidio?" Después de realizar el análisis de los testimonios fueron construidas categorías temáticas revelando, así, que el suicidio se les muestra a esos profesionales como algo que ocurre en un momento de mucha desesperación, a lo cual las personas recurren para llamar la atención y algo que les despierta una diversidad de sentimientos. Del análisis de los testimonios, fue posible comprender que el estudio evidencia necesidad de introducir profesionales especializados

\footnotetext{
${ }^{1}$ Trabalho realizado durante o Programa de Iniciação Científica - CNPq, 2003, sob orientação da segunda autora.

2 Enfermeira do Centro de Investigação Hematológica Dr. Domingos A. Boldrini - Campinas/SP. Rua Bernardino de Campos n³0 ap 1001 Centro - Ribeirão Preto, SP, CEP: 14015 -130, e-mail: vipicinato@hotmail.com

${ }^{3}$ Enfermeira. Professora Livre Docente (aposentada) da EERP - USP. Pesquisadora $1 A$ do CNPq. Rua César Lotito n’199, São Lázaro São João da Boa Vista - SP, CEP: 13870-460, Tel: (19) 3622-3672, e-mail: boemer@terra.com.br (Autor responsável pesla correspondência)
} 
en el área de salud mental. La especialización les permite a los profesionales trabajar mejor con los prejuicios y dificultades, abriendo así, perspectivas para cuidar mejor de las personas que no ven más sentido en la propia vida.

PALABRAS CLAVES: Suicidio, Intento de Suicidio; Salud Mental.

\section{INTRODUÇÃo}

Durante a trajetória para desenvolver um estudo cuja temática é a morte e o morrer foi preciso percorrer algumas etapas, o que incluiu a busca por conhecimentos sobre o tema em publicações, filmes, estágios, aulas e cursos que possibilitaram uma visão ampla da morte sob suas várias perspectivas. De todo esse percurso, uma faceta passou a inquietar-me o suicídio - impulsionando-me a desenvolver o presente estudo.

Nas últimas décadas, tem se observado, com grande preocupação, o aumento no número de casos de suicídio e tentativas de suicídio em muitos países do mundo. Resulta de um ato deliberado, iniciado e levado a cabo por uma pessoa com expectativa de um resultado fatal.

É uma das principais causas de morte de adultos jovens, situando-se entre as três maiores causas na população de 15 a 34 anos, para ambos os sexos. Isso representa uma grande perda para a sociedade, envolvendo pessoas jovens, nos anos produtivos da vida. Só existem dados disponíveis sobre tentativas de suicídio de alguns países; eles indicam que esse número pode ser até 20 vezes maior que o de consumados. Inúmeros trabalhos sobre o tema apontam que grande parte de pessoas que tenta o suicídio acaba por repetir inúmeras vezes esse comportamento, chegando, muitas vezes, a obter êxito. (CASSOLAR, 1991)

Para a psicanálise, o suicídio é uma situação psicótica. Isso não significa que a pessoa seja psicótica, mas que, no momento do ato, nela tenham se ativado núcleos e componentes psicóticos da personalidade que permaneciam inativos e neutralizados pelas partes não psicóticas da personalidade e que acabam por se manifestar em dado momento da crise. A tentativa geralmente está associada às fantasias que cada pessoa tem com relação à morte: busca de uma outra vida, desejo de ressurreição, reencontro com mortos, volta ao seio materno e retorno à vida intra-uterina, agressão e punição ao ambiente. (CASSOLAR, 1991)

Através de investigações em diferentes comunidades, observa-se, através dos tempos, que os meios utilizados para o suicídio quase sempre envolvem 0 uso de instrumentos cortantes e penetrantes, armas de fogo, envenenamento, métodos traumáticos de asfixia, salto de alturas e atirar-se sob veículos. Quanto aos aspectos dinâmicos dessa forma de comportamento autodestrutivo, fatores como dependência, agressão e hostilidade, culpa e angústia, apesar de sua reatividade, parecem constantes na dinâmica do suicídio.

Entretanto, mesmo sendo estudado em quase todas as partes do mundo, permanece ainda um grande enigma para as ciências do comportamento a relação do homem com sua vida e, por conseguinte, com sua morte.

CASSORLAR (1991) organizou uma coletânea de trabalhos de pesquisadores brasileiros que discutem o fenômeno do suicídio, partindo de referenciais variados como a psicanálise, a psiquiatria, a psicologia social, a educação, a reflexão filosófica. Essa coletânea apresenta temas relacionados à incidência, fatores suicidógenos, motivações, medidas profiláticas, infância e adolescência, vitimologia e educação. (CASSOLAR, 1991)

KASTENBAUM \& AISENBERG (1983) descrevem alguns fatores que podem levar uma pessoa a cometer suicídio. Ressaltam que as causas fundamentais devem ser procuradas na contextura psicobiológica do próprio indivíduo. Um pedido indireto de auxílio é feito através do próprio gesto suicida. (KASTENBAUM \& AISENBERG, 1983)

O sociólogo Durkheim, progenitor das teorias sociais acerca do suicídio, considera-o uma manifestação de um ato individual que, na 
sua essência, seria social. Define-o como "todo caso de morte que resulta direta ou indiretamente de um ato positivo ou negativo, praticado pela própria vítima, desde que a mesma saiba produzir esse resultado". Refere que cada sociedade, em cada momento de sua história, tem uma aptidão definida para o suicídio (DURKHEIM, 1996).

MARTINS \& BOEMER (2001), ao analisarem $O$ periódico norte americano denominado "OMEGA - Journal of Death and Dying", $\quad$ específico para publicações relacionadas à morte e ao morrer, puderam fazer um levantamento dos artigos publicados durante o período de 1980 a 1994. Nos artigos que abordam o suicídio como tema central observou-se a preocupação em caracterizar os fatores que influenciam sua ocorrência, sejam eles psicológicos, sócio-econômicos, religiosos ou patológicos. Alguns desses autores enfocaram a aceitação do suicídio pela sociedade e pela família e também sua aceitação como cultura e tradição. (MARTINS \& BOEMER, 2001)

ANGERAMI (1986) enfoca o trabalho psicológico e psicoterápico na orientação aos familiares dos pacientes e de pessoas que tentaram o suicídio, na divulgação de fatores sociais, políticos e econômicos concernentes ao desespero individual, fatores esses que merecem a atenção da opinião pública e das autoridades competentes e na reflexão e estudos sistematizados da temática do suicídio. (ANGERAMI, 1986).

SAMPAIO \& BOEMER (2000) elaboraram uma incursão pelas idéias da fenomenologia, particularmente pelo pensamento do filósofo Martin Heidegger. A compreensão da pessoa que decide colocar fim à sua existência pode se constituir, na perspectiva deste estudo, como um caminho para reconstrução e redimensionamento de suas perspectivas existenciais. Relatam ainda como os profissionais de saúde vêm lidando com esta faceta de morte que se encontra presente na rotina dos atendimentos das urgências em clínicas médica, psiquiátrica e cirúrgica. Ressaltam que há uma certa agressividade, desprezo, preconceito e incompreensão dos profissionais em torno da pessoa que tenta por fim à sua existência. (SAMPAIO \& BOEMER, 2000)

Atualmente, 0 ato suicida tem como característica ser clandestino, ou seja, sem testemunhos, dissimulado, ocorrendo como se estivesse transgredindo regras expressas por nossa sociedade capitalista na qual a morte é banida, não enfrentada e evitada.

VANSAN (1978) observou, no município de Ribeirão Preto, o possível relacionamento do suicídio com algumas características pessoais como sexo, idade, estado civil, níveis profissionais, cor, bem como o meio utilizado e necessidade de hospitalização.(VANSAN, 1978) Esse autor, em outro estudo, analisou o índice de mortalidade por suicídio e também seus aspectos sociais, clínicos e psicodinâmicos. (VANSAN, 1981)

Andrade estudou a distribuição de casos de tentativa de suicídio, também no município de Ribeirão Preto, durante o ano de 1977. Realizou um estudo epidemiológico descritivo, considerando as variáveis relacionadas à pessoa, tempo,lugar e agente utilizado.(ANDRADE, 1979).

Ficher analisou, nesta mesma cidade, as tentativas ocorridas entre os adolescentes. O objetivo de seu trabalho foi caracterizar as tentativas, verificar sua distribuição temporal e analisar comparativamente com o uso/abuso de substâncias psicoativas.(FICHER, 2000)

Utilizando o Sistema de Arquivo Médico (SAM) do Hospital das Clínicas da Faculdade de Medicina de Ribeirão Preto, realizei um levantamento da demanda de pacientes que chegaram à Unidade de Emergência, no período de janeiro de 1998 a dezembro de 2001, por tentativa de suicídio. Os dados indicam que foram atendidos 1332 pacientes nesse período, sendo que 462 foram na clínica psiquiátrica e o restante nos demais setores da Unidade.

A Unidade de Emergência está inserida no Sistema de Saúde e faz parte do Hospital das Clínicas de Ribeirão Preto. Atende pessoas de toda a região deste município, as 
quais necessitam de um cuidado mais complexo que aquele que é dado nas Unidades Básicas de Saúde. A clínica psiquiátrica é composta por seis leitos. São atendidos nesse local os pacientes com transtornos mentais, entre os quais vários que já apresentaram tentativas de suicídio.

Durante 0 estágio curricular de Enfermagem Psiquiátrica pude observar que o paciente, ao ser admitido nessa clínica, passa por uma consulta médica na qual é estabelecida a conduta a ser tomada. Muitos chegam agressivos e acabam por serem sedados e restringidos no leito. O médico que atende esses pacientes não está imune ao impacto causado pela tentativa de suicídio ou pode não dar importância ao ato por desconhecimento do tema ou por negação de seus sentimentos. Preconceitos e dificuldades pessoais geralmente fazem com que 0 profissional menospreze a importância da tentativa de suicídio. (SAMPAIO \& BOEMER, 2000)

Frente às minhas observações e à consulta à literatura, surgiu-me uma inquietação: Será que os profissionais que atuam em setores dessa natureza estão preparados para lidar com isso? É difícil dizer como os profissionais devem lidar com essas pessoas. Afinal, conforme referem muitos autores, eles são preparados para salvar vidas, não para lidar com a morte. Muitos relatam sua impotência e frustração perante a imprevisibilidade da trajetória da morte. É como se nesses momentos estivessem diante da fragilidade de suas existências, reportando-se à sua própria terminalidade e à possibilidade de viver a mesma situação de seus pacientes. A negação pode surgir como uma forma de defesa para não entrar em contato com essa fragilidade. (CASSORLA, 1991)

Não há médico ou equipe que não sofra o impacto violento do suicídio. Os membros da equipe de saúde captam a agressividade do ato e o percebem como um ataque a eles mesmos, surgindo sentimentos de impotência, frustração e fragilidade. A equipe precisa lidar com o ato suicida como um sintoma de um quadro mais complexo, que deve ser investigado, identificado e combatido com estratégias adequadas.

Assim, diante da gênese da inquietação mencionada, em conjunto com a orientadora do Programa de Iniciação Científica, planejamos e desenvolvemos $o$ presente trabalho que se propõe a des-velar como o suicídio se mostra, em sua essência, a profissionais que atuam neste setor específico. Nesse sentido, a redação do presente estudo passa, a partir de agora, para a primeira pessoa do plural, expressando o compartilhamento da investigação. O suicídio em seu mostrar-se a profissionais de saúde é algo que se mostra oculto para nós, pedindo por um des-velamento.

\section{MATERIAL E MÉTODO}

O estudo foi conduzido segundo a Metodologia de Investigação Fenomenológica, dado que a natureza do objeto de pesquisa é pertinente a esse referencial teórico metodológico de investigação.

O método fenomenológico tem como enfoque central a compreensão dos fenômenos, dirigindo-se para a vivência cotidiana. Seu objetivo é chegar à apreensão intelectual da verdadeira realidade, que é o mundo das essências. Segundo TURATO (2003), a fenomenologia tem sido a principal base filosófica para as metodologias qualitativas atuais, tendo o homem por seu objeto de estudo, conforme aponta amplamente a literatura, inclusive para os métodos empregados na área da saúde e da clínica. TURATO (2003)

A fenomenologia põe em evidência que os seres humanos não são objetos e que suas atitudes não podem ser vistas como simples reações. Sua preocupação será com a essência através dos fenômenos. (MARTINS et al, 1990). A pesquisa fenomenológica não se direciona para 0 caráter quantitativo das entrevistas realizadas, mas busca por dados qualitativos. O momento da entrevista para obtenção de dados não pode ser visualizado 
como um procedimento mecânico, mas como um encontro social, uma relação pesquisador pesquisado, caracterizado pela empatia, intuição e imaginação. (CORREA, 1997).

Os depoimentos obtidos de uma interrelação empática levam à compreensão do fenômeno vivido investigado e não à sua explicação. Portanto, importa a cada investigador "buscar" a melhor forma de aproximação aos seus depoentes, levando em consideração o alcance dos objetivos propostos e aspectos que propiciem ou facilitem o "encontro social", as particularidades da clientela escolhida, a adequação da questão norteadora e da técnica de obtenção dos depoimentos. (SIMÕES \& SOUZA, 1997).

Para realizar a coleta de dados são utilizados os métodos de observação, entrevista e análise documental. "O importante é manter uma atitude flexível e aberta, admitindo que outras interpretações possam ser sugeridas, discutidas e igualmente aceitas." (LUDKE \& ANDRÉ, 1985),

O estudo foi realizado no período de julho a agosto de 2003, após obtenção do aval do Comitê de Ética em Pesquisa. Contou com a participação de profissionais médicos residentes de Psiquiatria e do Programa de Saúde da Família, enfermeiros sem especialização na área e auxiliares de enfermagem que trabalham na Clínica Psiquiátrica da Unidade de Emergência. As entrevistas foram realizadas pela autora que apresentava-se e expunha a proposta do estudo. Vale a pena ressaltar que houve algumas recusas por parte da equipe, as quais foram respeitadas. Após obter o consentimento em participar da pesquisa, era proposta a seguinte questão norteadora: Como o suicídio se mostra a você?.

Os depoimentos foram gravados de acordo com a permissão dos profissionais e, posteriormente, foram transcritos na sua íntegra. Para aqueles que não permitiram gravar, elaboramos um relato da entrevista após seu término.*

Os depoimentos foram coletados até o momento em que foi possível visualizar convergências, divergências, similaridades nas falas dos profissionais, totalizando onze depoimentos.

\section{RESULTADOS E DISCUSSÃO}

Os dados foram analisados segundo o referencial fenomenológico, de acordo com o preconizado por MARTINS \& BICUDO (1989).

A análise fenomenológica dos depoentes foi realizada da seguinte forma:

Leitura dos depoimentos, por várias vezes, a fim de familiarizar-nos com os mesmos e obter um sentido do todo.

Retomada da leitura, tendo em vista a minha interrogação inicial: Como o suicídio se mostra a profissionais de saúde?. Desta forma, foi possível identificar as unidades de significado.

Busca das convergências entre as unidades de significados (elementos comuns a vários discursos) e as divergências (elementos que são peculiares a apenas um ou a poucos discursos).

Elaboração de uma síntese descritiva, integrando as afirmações significativas em categorias temáticas, buscando a compreensão de como o suicídio se mostra, em sua essência, a profissionais de saúde, expressando os significados atribuídos por eles.

Após realizar essa análise pudemos construir as seguintes categorias temáticas, as quais se constituem em facetas de essência desse mostrar-se. De toda a análise, o que se desvelou é que o suicídio se mostra a esses profissionais como:

\section{- Algo que ocorre a uma pessoa num momento de muito desespero}

As falas dos profissionais entrevistados revelam que, sob sua ótica, de uma forma geral, o suicida está tentando fugir de uma situação de sofrimento que chega aos limites do insuportável. Mostra-se como um pedido de ajuda, ocorrendo num momento de muito 
desespero. Vejamos algumas falas que expressam essa percepção:

"Aí ele fica desesperado e tenta se matar". ${ }^{1}$

“... é um ato na maior parte das vezes

desesperado, de muito sofrimento." 10

“... é uma forma de o paciente pedir ajuda de alguma forma." 11

$\mathrm{O}$ ato de tentativa de suicídio é visto como um grito de socorro. Em um dos discursos, o profissional refere que uma pessoa que não tem recursos para superar as reações e as adversidades pelas quais está passando, escolhe acabar com a própria vida como forma de superar esses problemas. Não existe nenhuma teoria que possa explicar todos os casos e situações de comportamentos suicidas. A pessoa, não suportando mais tanto sofrimento, vê na morte o único descanso, a única saída para aliviar a tensão.

Para alguns, o suicida é caracterizado por apresentar certa carência. Pode ser carência afetiva, emocional; enfim, é uma pessoa que precisa de atenção, de apoio, de afeto.

Os profissionais mencionam que 0 suicídio ocorre principalmente por causa dos problemas sociais, da violência, da falta de estrutura, problemas familiares, afetivos, financeiros, pressão no trabalho, enfim, por estressores do cotidiano. Há autores que corroboram esses achados quando referem que a pessoa faz isso pelo fato de vivenciar a percepção de que ela não tem peso na sociedade em que vivem; uma sensação de menos valia. Sua estrutura emocional ou estrutura psíquica está mal adaptada à realidade em que vive. $\mathrm{Na}$ sociedade de hoje, há registros de muitos idosos que tentam se matar. O motivo que apresentam é que estão no fim da vida e não têm mais razão para viver. Além disso, há um grande índice de adolescentes que realizam tal ato, principalmente para chamar atenção para seus problemas.

Os profissionais do presente estudo, apesar de atribuírem o significado de pedido de ajuda ao ato suicida, também revelam, em suas falas, uma outra faceta que, embora não se contraponha à primeira, vem permeada por menor grau de compreensão existencial do gesto suicida. A próxima categoria temática construída revela essa outra faceta.

\section{- Algo ao qual as pessoas recorrem para chamar atenção}

Nos discursos dos profissionais é possível visualizar que alguns entendem a tentativa de suicídio como uma forma de chamar atenção. Relatam que, quando a pessoa avisa que vai se matar, ela faz isso apenas para chamar atenção.

\section{“... faz chantagem, só pra chamar atenção." 2}

Entendem que há uma chantagem com a intenção de agredir ou provocar culpa nas outras pessoas. A tentativa de suicídio consiste, assim, num gesto calculado para impressionar, assustar, ou forçar pessoas com quem o paciente está em contato a dar-lhe atenção e prestar-lhe favores. Fazem chantagem com a intenção de agredir ou provocar culpa nas outras pessoas.

“... talvez eu acho que aquela tentativa não deu o resultado que eles queriam, de chamar atenção de quem eles queriam. "11

Num dos relatos, a profissional diz compreender os pacientes psiquiátricos porque eles têm problemas, são doentes. Por outro lado, refere que as pessoas que chegam ao hospital, que tentaram o suicídio tomando altas doses de medicamentos, por exemplo, as quais têm que fazer lavagem gástrica, passar carvão etc, tudo isso é pra chamar atenção. Entendem que "quem quer se matar, se mata de uma vez".

Conflitos relacionados à explosão instintiva da adolescência, desejos genitais edípicos, conflitos relacionados à 

saúde. Revista Eletrônica de Enfermagem, v. 06, n. 02, p. 143-152, 2004. Disponível em www.fen.ufg.br

dependência/independência dos pais, conflitos bissexuais, estabelecimento de uma identidade adulta são fatores que podem levar à tentativa de suicídio por adolescentes. (CASSORLA, 1991). Eles sentem-se rejeitados, desprezados, uma carga para os pais. A ação autodestrutiva ocorre aí como uma tentativa de conseguir o perdão e o carinho dos pais.

Há, num dos relatos, uma citação de que existem pacientes que fantasiam seu próprio velório. Eles imaginam que depois que morrem vão ver esse velório e as pessoas que eles gostam chorando por eles. Fantasiam tanto que acabam tentando o suicídio. Muitos realizam tal ato com o objetivo de conhecer e saber como é o outro lado.

“.. por uma bagagem cultural ou religiosa, ou por uma crença de vida que ela tenha, de como a vida é depois da morte e tudo mais... ela acaba tentando de uma forma ou de outra acabar com a vida dela." 10

Atualmente $\mathrm{o}$ ato suicida tem como característica ser clandestino, ou seja, sem testemunhos, dissimulado, ocorrendo como se estivesse transgredindo regras expressas por nossa sociedade capitalista na qual a morte é banida, não enfrentada e evitada.

Na Idade Média, matar-se equivalia a um sacrilégio e o suicida era considerado como não merecedor da misericórdia divina, não recebendo a salvação de sua alma. A presença da religião ainda é constante, podendo ser observada no seguinte relato:

"Alguns pacientes que têm um ambiente mais religioso, eles têm muitas vezes essa vontade... mas eles não fazem isso porque acreditam que não vão ter salvação, que vão para o inferno." 10

A tentativa de suicídio é associada às fantasias que cada pessoa tem com relação à morte: busca de uma outra vida, desejo de ressurreição, reencontro com mortos, volta ao seio materno e retorno à vida intra-uterina, agressão e punição ao ambiente. (CASSORLA, 1991).

Não é fácil para os profissionais lidarem com isso. Muitas dificuldades são enfrentadas ao lidar com atos autodestrutivos e mesmo com o risco de que eles ocorram.

\section{- Algo que Ihes desperta uma diversidade de sentimentos}

Muitos dos profissionais percebem as dificuldades de trabalhar com o suicida e, conseqüentemente, com o suicídio. Há uma certa preocupação em dar um acompanhamento aos pacientes, realizando assim, um trabalho mais amplo. Percebem que a estrutura da Instituição não permite um cuidado mais abrangente. Surgem, então, sentimentos de culpa, impotência, frustração, fragilidade e desespero perante 0 ato autodestrutivo.

"O problema daqui é que mesmo que a gente cuide de um paciente que tentou o suicídio, não sabemos o que vai acontecer com ele depois que for embora." 3

"Às vezes, eu me sinto mal por não conseguir ajudar um paciente da maneira que ele precisa." 4

Mesmo havendo essa preocupação em realizar um trabalho mais adequado com essas pessoas, ainda existem profissionais que chegam a lidar com o paciente com um desprezo agressivo, às vezes chegando próximo ao maltrato, evidenciando uma incompreensão para com a pessoa que atenta contra sua vida. . ${ }^{1}$

"Não tenho preconceito em atender paciente com tendência suicida... Tenho paciência... tenho compaixão, às vezes até dó das pessoas.... Acho que é muito ${ }_{5}$ difícil para um profissional lidar com isso."

"Às vezes, a gente precisa ser um pouco áspero com o paciente mas, muitas 
vezes, precisamos ser dóceis para poder conversar e ajudar essa pessoa." 7

O fato do profissional se defrontar com um gesto suicida não deve impedí-lo de investigar conflitos ou desejos de morte ainda inaparentes e, principalmente, deve alertá-lo a não menosprezar as necessidades emocionais de seu paciente. Os profissionais precisam estar alertas diante da possibilidade de atos suicidas e, além da investigação das fantasias do paciente, poder examinar seus próprios sentimentos.

\section{CONSIDERAÇÕES FINAIS}

No decorrer das entrevistas, chamou-nos atenção o fato que, dos onze profissionais entrevistados, seis não permitiram a gravação de suas falas. Alguns referiram sentirem-se inibidos perante um gravador; outros não se justificaram, levando-nos a uma nova interrogação: Será esse um assunto tabu, do qual eles têm medo de falar, ou será que eles não querem deixar registro formal de sua fala? Se assim for, qual seria o receio que se mostra velado?

Outra inquietação surgiu-nos quando houve recusa por parte de alguns profissionais em participar deste estudo. O que impede que esse profissional revele seu pensar? Esse silêncio também é uma forma de discurso. (BEANINI, 1981).

Quando retornamos à minha inquietação inicial: "como o suicídio se mostra a profissionais de saúde", percebemos que esses relacionam sempre o suicídio (fato) a uma pessoa. Nesse caso, o suicídio não é um fator abstrato, e sim algo concreto, que eles já presenciaram, remetendo, assim, a uma experiência vivida.

Em algumas falas é possível perceber que o suicídio se mostra aos profissionais como um pedido de ajuda, um pedido de socorro, algo que ocorre num momento de muito desespero. De uma forma geral, entendem que o suicida está tentando fugir de uma situação de sofrimento que chega aos limites do insuportável.

Por outro lado, há aqueles que acham que a tentativa de suicídio é uma forma que as pessoas encontram para chamar atenção. Um dos profissionais, em seu relato, diz compreender os pacientes psiquiátricos porque eles têm problemas, são doentes. Porém, acredita que outras pessoas que tentam o suicídio fazem chantagem só para chamar atenção. Sob nossa ótica, é preocupante essa forma de pensar, pois trata-se de profissionais que lidam diariamente com essas pessoas e acabam por manifestar certos preconceitos, menosprezando a importância da tentativa de suicídio.

Manifestou-se também a importância de ficar atento às reações do paciente. Alguns profissionais se preocupam quando a pessoa fala que quer se matar; outros dão mais importância ao silêncio do paciente, entendendo que precisam ficar muito atentos:

"... se o paciente fala que quer se matar, preciso ficar atento, mas se percebo que ele está quieto, calmo, apenas observando, aí é preciso dobrar a atenção, pois quando menos a gente espera, ele tenta se matar." 7

A presença da família foi pouco mencionada nos discursos. Há citações de que ocorre desprezo da família; às vezes, os familiares não dão muita atenção ou ainda a pessoa não tem diálogo com eles, gerando muitos problemas.

Houve por parte de alguns profissionais a preocupação em dar um acompanhamento aos pacientes. Chega a existir certa frustração e impotência diante da dúvida do que irá acontecer quando o paciente voltar pra casa. Nesse sentido, há um caminho a percorrer entre a internação da pessoa que tenta o suicídio e uma efetiva interligação com os Programas de Saúde Mental, após a alta hospitalar.

Cabe ressaltar que, em alguns relatos, os profissionais percebem a dificuldade de lidar 
com o suicida e, conseqüentemente, com o suicídio. Porém, percebemos que há uma maior preocupação por parte dos profissionais médicos entrevistados em realizar um trabalho mais amplo com essas pessoas.

"Cabe a nós como profissionais da área de saúde mental tentar proteger essas pessoas e ajudá-las." 10

termo "proteção" aqui utilizado ganha uma dimensão bastante pertinente e um efetivo Sistema de Saúde precisa ter essa proposta. Essas pessoas precisam ser protegidas e, ao nosso ver, o primeiro passo para protegê-las é a compreensão. Conforme já salientado, é preciso compreendê-las nessa decisão e, a partir de seu horizonte de possibilidades, ajudá-las a redimensionar seus projetos de vida, abrindo fendas para novas possibilidades existenciais. ${ }^{6}$ Paradoxalmente, na medida em que as compreendemos na sua decisão de não ser mais aí no mundo, fazemos um primeiro movimento de protegê-las e acolhê-las, numa perspectiva existencial.

Da análise dos depoimentos, pudemos compreender que o estudo abre perspectivas para introduzir, na área de saúde mental, profissionais especializados. É visível a diferença do significado atribuído ao suicídio por médicos (especializados e em especialização) e por enfermeiros e auxiliares que não apresentam especialização psiquiátrica. A especialização possibilita aos profissionais lidar melhor com os preconceitos e dificuldades, abrindo, assim, perspectivas para um melhor cuidado às pessoas que não vêem sentido na própria vida.

\section{REFERÊNCIAS BIBLIOGRÁFICAS}

CASSORLA, R. M. S. Do Suicídio - Estudo Brasileiros. Campinas, Papirus, 1991.

KASTENBAUM, R, AISENBERG, R. Psicologia da Morte. Tradução de Adelaide Petters Lessa. São Paulo: Pioneira 1983.

DURKHEIM, E. O Suicídio. $6^{a}$ edição. Lisboa, Presença, 1996.
MARTINS, M.M.; BOEMER, M. R. Produção científica sobre o tema da morte e do morrer: estudo de um periódico. Rev. Gaúcha Enf., v.22, n.2, p.141 - 156, 2001.

ANGERAMI, V. A.. Suicídio: uma alternativa à vida, uma visão clínica - existencial. São Paulo: Traço, 1986.

SAMPAIO, M .A.; BOEMER, M. R. Suicídio um ensaio em busca de um des-velamento do tema. Rev Esc Enf. USP, v. 34, n. 4, p. 325-31, 2000.

VANSAN, G. A. Estudo da mortalidade por suicídio no município de Ribeirão Preto. Ribeirão Preto, 1978, 265p., Dissertação (Mestrado). Faculdade de Medicina de Ribeirão Preto da Universidade de São Paulo.

VANSAN, G. A. Suicídio: aspectos sociais, clínicos e psicodinâmicos. Preto. Ribeirão Preto, 1981, 173p, Tese (Doutorado). Faculdade de Medicina de Ribeirão Preto da Universidade de São Paulo.

ANDRADE J. J. B. Epidemiologia da tentativa de suicídio em Ribeirão Preto. Ribeirão Preto, 1979, 95p., Dissertação (Mestrado). Faculdade de Medicina de Ribeirão Preto da Universidade de São Paulo.

FICHER A. M. F. T. Tentativas de suicídio de adolescentes atendidos no setor de urgências psiquiátricas de um hospital geral. Ribeirão Preto, 2000. 81p. Dissertação (Mestrado). Escola de Enfermagem de Ribeirão Preto da Universidade de São Paulo.

TURATO E. R. Tratado da metodologia da pesquisa clinico-qualitativa: construção teóricoepistemológica, discussão comparada e aplicação nas áreas da saúde e humanas. Petrópolis: Vozes, 2003.

MARTINS M. M., BOEMER M.R., FERRAZ C.A.. A Fenomenologia como Alternativa Metodológica para Pesquisa - Algumas Considerações. Rev. Esc. Enf. USP, v. 21, n. 1, p. 139-47, 1990:

CORRÊA A. K. Fenomenologia: Uma Alternativa para Pesquisa em Enfermagem. Rev. Latino-Am Enf., v. 5, n. 1, p. 83-88, 1997. SIMÕES S. M. F., SOUZA I. E. O. Um Caminhar na Aproximação da Entrevista 

saúde. Revista Eletrônica de Enfermagem, v. 06, n. 02, p. 143-152, 2004. Disponível em www.fen.ufg.br

Fenomenológica. Rev. Latino-Am Enf., v. 5, n. 3, p. 13-7, 1997.

LUDKE M., ANDRÉ M.E.D.A.. Pesquisa em Educação: Abordagens Qualitativas. São Paulo. Editora Pedagógica e Universitária, 1986.

MARTINS J.; BICUDO M. A. V. A pesquisa qualitativa em psicologia: fundamentos e recursos básicos. São Paulo: Moraes, 1989.
BEANINI T;C;. À escuta do silêncio (Um estudo sobre a linguagem no pensamento de Heidegger). São Paulo, Cortez, 1981.

Texto recebido em 04/05/2004

Aprovado para publicação em 31/08/200 